\title{
Vulnerabilidade a erosão e aplicações socioambientais no Baixo Interflúvio Madeira-Purus, AM/RO
}

A ocupação no Baixo Interflúvio Madeira-Purus tem gerado reflexões com relação de sustentabilidade ambiental. Umas das principais preocupações é que a revitalização da BR-319 provoque: conexão desta área com o arco de desmatamento e vigorosa antropização. Assim, o presente trabalho tem como objetivo analisar a morfodinâmica da paisagem com o funcionamento dinâmico entre os sistemas geoambientais envolvidos do Baixo Interflúvio Madeira-Purus, identificando restrições de porções do terreno com relação vulnerabilidade a erosão e aplicações socioambientais. O método utilizou o princípio da ecodinâmica de Tricart (1977), a partir da integração geoespacial proposta por proposta por Crepani et al. (1996; 2001) e validação em campo. Como resultado foi possível distinguir as classes de vulnerabilidade a erosão estável $(0,47 \%)$, moderadamente estável $(37,26)$, medianamente estável/vulnerável $(61,09 \%)$ e moderadamente vulnerável $(1,18 \%)$ distribuídas na paisagem do Baixo Interflúvio Madeira-Purus. Nas porções do terreno que apresentam características de medianamente vulnerável/estável e moderadamente vulnerável a erosão, mesmo com relativos baixos índices de vulnerabilidade processos erosivos laminares e lineares intensos são identificados, sendo desencadeados pela supressão da vegetação natural, implantação de obras de infraestrutura e atividades agropecuárias.

Palavras-chave: Morfodinâmica; Vulnerabilidade a Erosão; Interflúvio Madeira-Purus; Geoprocessamento.

\section{Vulnerability to erosion and socio-environmental applications in the Lower Interfluvium Madeira-Purus, AM/RO}

\begin{abstract}
Occupation in Madeira-Purus Lower Interfluve generates thoughts regarding environmental sustainability. One of the biggest concerns is that reconstructing the highway BR-319 causes a connection between this area and the Arc of Deforestation, besides an intense anthropic action. The present work aims to analyse the morphodynamics of the landscape with dynamic operation between the involved geoenvironmental systems of Madeira-Purus Lower Interfluve identifying restrictions in portions of the terrain with relation vulnerability to erosion and socio-environmental application. The method used the principle of ecodynamics of Tricart (1977) from the Geospatial integration proposed by Crepani et al. $(1996 ; 2001)$ and field validation. As a result, it was possible to differentiate classes of vulnerability, stable erosion $(0,47 \%)$, moderately stable $(37,26 \%)$, intermediate stable/vulnerable $(61,09 \%)$ and moderately vulnerable $(1,18 \%)$ disposed in the landscape of Madeira-Purus Lower Interfluve. In portions of the terrain which show characteristics of intermediate vulnerable/stable and moderately vulnerable to erosion, even with low index of vulnerability, intense processes of laminar em linear erosion are identified, being triggered by the suppression of natural vegetation, implementation of infrastructure work and agriculture and cattle activities.
\end{abstract}

Keywords: Morphodynamics; Vulnerability to erosion; Madeira-Purus interfluve; Geoprocessing.

Topic: Desenvolvimento, Sustentabilidade e Meio Ambiente

Reviewed anonymously in the process of blind peer.
Received: 03/03/2021

Approved: 26/03/2021
Marcio Felisberto da Silva

Universidade Federal de Rondônia, Brasil http://lattes.cnpq.br/1904880577882889 felisbertomarcio@gmail.com

Vanderlei Maniesi (D)

Universidade Federal de Rondônia, Brasil http://lattes.cnpq.br/6309486071440042 http://orcid.org/0000-0003-0369-6069 vanmaniesi@hotmail.com

Reginaldo Martins da Silva de Souza Universidade Federal de Rondônia, Brasil http://lattes.cnpq.br/6030930058307437 reginaldo.martins@ifro.edu.br
Referencing this:

SILVA, M. F.; MANIESI, V.; SOUZA, R. M. S.. Vulnerabilidade a erosão e aplicações socioambientais no Baixo Interflúvio Madeira-Purus, AM/RO. Revista Ibero Americana de Ciências Ambientais, v.12, n.3, p.598-612, 2021. DOI: http://doi.org/10.6008/CBPC21796858.2021.003.0048 


\section{INTRODUÇÃO}

Projetos de desenvolvimento racionalizados para Amazônia intensificaram o processo migratório e desencadearam uma série de mudanças neste ambiente, resultando em perdas ecológicas de grandes dimensões (FEARNSIDE et al., 2009). No Baixo Interflúvio dos rios Madeira e Purus os processos de ocupação e de desflorestamento mostram-se de natureza diferenciada. Por exemplo, enquanto no município de Humaitá projetos de Assentamento rurais federais representam, em média, cerca de $20 \%$ de seu desflorestamento (LEAL et al., 2018a), no município de Manicoré são verificadas as maiores taxas de desflorestamento no estado do Amazonas com atividades relacionadas à agropecuária com sua maior parte ocorrendo fora dos assentamentos rurais federais (LEAL et al., 2018b). Outro fato relevante referente a área de estudo, trata-se da reconstrução e asfaltamento da Rodovia BR-319 prevista como obra de infraestrutura do governo federal, a qual atualmente encontra-se em fase de licitação para o denominado "Trecho do Meio" (BRASIL, 2019). Esta obra pode promover perdas ecológicas e sociais de grandes dimensões tanto ao longo da rota da rodovia quanto da possibilidade de conexão com o arco de desmatamento à Amazônia central, com o início de um novo ciclo migratório descontrolado para essas regiões remotas, hoje sem acesso por estradas, como menciona Fearnside et al. (2009).

Neste contexto de ocupação territorial do espaço amazônico, os recursos dos elementos do ambiente como variável inversa à conservação ou limitação com impactos ao ambiente muito além da sua área de influência, tem-se favorecido o uso intensivo e extensivo de seus recursos naturais que retroalimentam e aceleram processos de desmatamento e degradação ambiental (FEARNSIDE, 1989; 1993). Influências antrópicas como estruturação ou reestruturação de sistemas de circulação no espaço amazônico proporcionam modificações do funcionamento dinâmico e concorrente dos elementos do ambiente natural. A compreensão dessa dinâmica de sustentabilidade socioambiental inter e intrarregional mostra-se de fundamental importância no Baixo Interflúvio Madeira-Purus, dada as suas potencialidades e fragilidades naturais relacionadas aos processos morfogenéticos e pedogenéticos na perspectiva de uma relação sociedade-natureza de ordenação desse espaço interfluvial, com maior justiça social e conservação dos recursos naturais. Sendo assim, este trabalho objetiva analisar a morfodinâmica da paisagem do Baixo Interflúvio Madeira-Purus, identificando potencialidades de porções do terreno com relação a vulnerabilidade a erosão e aplicações socioambientais.

O processo de ocupação do Estado de Rondônia, impulsionado sobretudo a partir da década de 1970 com os projetos de assentamento do governo federal, resultou na alteração da dinâmica de parte do ambiente natural a partir da intervenção por meio do uso e ocupação antrópica. Nesse período, o objetivo do governo era atrair o fluxo migratório até o sul do Estado do Amazonas, o que justificava a construção e pavimentação da rodovia BR-319, que ocorreu ainda na década de 1970, porém o Estado de Rondônia absorveu a população do fluxo migratório o que não ocorreu ao longo da BR-319 como se esperava. Na atualidade, com o avanço da expansão da fronteira agropecuária de Rondônia em direção ao sul do Amazonas, seguido da especulação imobiliária, fortalece o discurso da necessidade da revitalização da 
rodovia BR-319 como sendo a única ligação rodoviária do estado do Amazonas com o restante do Brasil, com favorecimento para o transporte de pessoas, escoamento de produtos para os mercados interno e externo, especialmente os agropecuários, e da produção industrial da Zona Franca de Manaus. No entanto, essa demanda de obras que possibilita o uso e ocupação do Baixo Interflúvio Madeira-Purus, ainda possui o mesmo paradigma de relação sociedade-natureza abordado por autores como Becker (2005), baseado na contínua incorporação de terra e de recursos naturais que são percebidos como infinitos, com povoamento regional localizado ao longo de rodovias, não mais ao longo da rede fluvial como no passado, e no crescimento demográfico, sobretudo urbano. Para essa relação sociedade-natureza, também há a tendência de conexão do arco de desmatamento à Amazônia central, onde se encontra o Baixo Interflúvio MadeiraPurus, com perdas ecológicas significativas (FEARNSIDE et al., 2009). Como perdas ecológicas surge a preocupação com relação aos possíveis desequilíbrios entre os elementos que compõem a paisagem a partir da iminente influência da pressão antrópica sobre seus recursos naturais (BRASIL, 2019), necessitando, assim, da compreensão de suas limitações morfordinâmicas de ocupação com relação a vulnerabilidade a erosão. A análise dos elementos da paisagem natural (Geologia, Geomorfologia, Pedologia, Intensidade Pluviométrica e Vegetação) inter-relacionados configurando um ambiente geodinâmico complexo, envolve processos morfogenéticos e pedogenéticos em proporções variadas e possibilita previsões de estimativas de estabilidades e instabilidades a erosão como parte essencial na evolução de paisagens (CREPANI et al., 2001), com base no princípio da ecodinâmica de Tricart (1977).

O Baixo Interflúvio Madeira-Purus está compreendido entre a margem esquerda do rio Madeira e a margem direita do rio Purus, possuindo uma área de 14.112.273,39 hectares. Abrange os municípios de Porto Velho, Lábrea, Canutama, Humaitá, Tapauá, Manicoré, Beruri, Novo Aripuanã, Borba, Manacapuru, Itacoatiara, Iranduba, Manaquiri, Careiro, Autazes e Careiro da Várzea, sendo o primeiro pertencente ao estado de Rondônia e os demais ao estado do Amazonas (Figura 1). O principal acesso é terrestre e realizado pela BR-319, que liga Porto Velho/RO a Manaus/AM.

A geologia da área de estudo (AMAZONAS, 2011) é constituída por rochas paleoproterozoicas polideformadas e metamorfizadas como embasamento rochoso regional (Complexo Jamari) e rochas mesoproterozoicas de natureza granítica (Suíte Intrusiva Teotônio e Suíte Intrusiva Santo Antônio). Sobre as quais desenvolvem coberturas cenozoicas tanto sedimentares do Mioceno e Plioceno (Formação Içá) e do Holoceno (Aluviões), quanto detrito-laterítica do pleistoceno. Quanto a geomorfologia, na área de estudo desenvolvem-se as unidades morfoestruturais Planície Amazônica e o Planalto Rebaixado da Amazônia Ocidental. A primeira refere-se às áreas inundadas e inundáveis, que abrangem as planícies dos rios Purus e Madeira, além das calhas dos afluentes mais próximos desses rios. Já a segunda unidade morfoetrutural refere-se às extensas áreas de interflúvio com relevo dissecado com formato tabular.

As unidades morfoestruturais são compartimentadas nas unidades Planície Amazônica, Depressão do Ituxi-Jari e Depressão Madeira-Purus (AMAZONAS, 2011). Em relação a pedologia, na área de estudo são encontrados solos do tipo Argissolos, Latossolos, Cambissolos, Espodossolos, Plintossolos, Gleissolos, Neossolos e Planossolos, desenvolvidos sobre rochas pré-cambrianas e coberturas cenozoicas (IBGE, 2007; 
AMAZONAS, 2011). A vegetação que se desenvolve no Baixo Interflúvio do rio Madeira-Purus é constituída por fitofisionomias do tipo Florestas Ombrófilas, Formações Pioneiras, Savanas e Áreas de Contato.

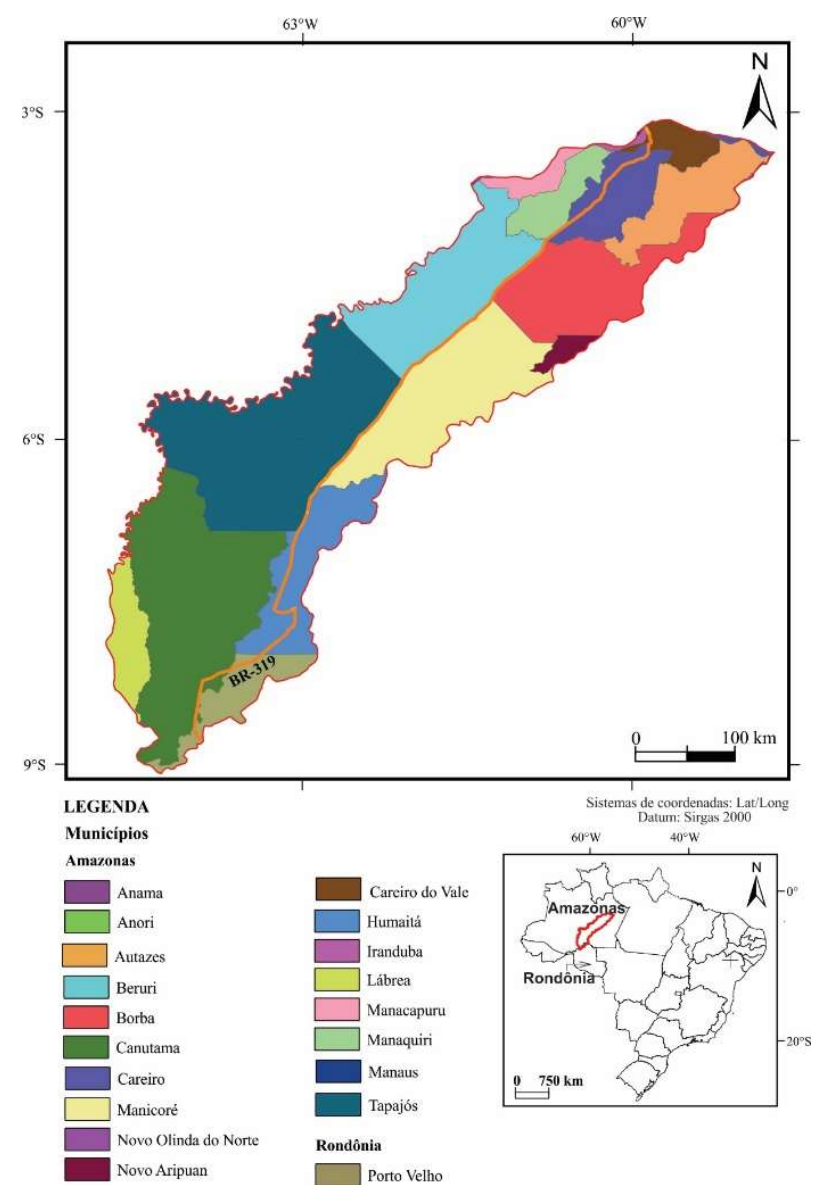

Figura 1: Localização da área de estudo.

A hidrografia da área do Baixo Interflúvio Madeira-Purus totaliza dezesseis sub-bacias, pertencentes a dois grandes rios de abrangência internacional. O Madeira, na porção direita, e Purus, na porção esquerda. O rio Madeira, uns dos principais rios da bacia Amazônica, nasce a partir da confluência dos rios Beni e Mamoré, fronteira entre Brasil e Bolívia e deságua na margem direita do rio Amazonas e possui 1.135 km de comprimento de canal na abrangência da área de estudo. O rio Purus, por sua vez, nasce no Peru e adentra o território brasileiro percorrendo os estados do Acre e Amazonas, desagua na margem direita do rio Solimões e possui 1.270 km de comprimento de canal no Baixo Interflúvio Madeira-Purus.

O clima em que a área de estudo está inserida é classificado como Tropical Chuvoso (Aw). A precipitação e temperatura apresentam desigual distribuição espacial e sazonal. Na porção central do Baixo Interflúvio Madeira-Purus a média anual é de $2.300 \mathrm{~mm}$, enquanto que em sua extremidade sul, nas proximidades de Porto Velho, RO, a média é de $2.200 \mathrm{~mm}$, e na outra extremidade, próximo à cidade de Manaus, AM, a média anual varia de 2.200 a $2.000 \mathrm{~mm}$. Os meses de novembro a março são considerados os mais chuvosos e o período 26 de maio a setembro os mais secos. No que se refere às temperaturas médias, estas variam de 24 a $26^{\circ} \mathrm{C}$ em sua porção central da área de estudo. Na porção sul, na abrangência de Porto Velho, RO, e Lábrea, AM, temperatura média anual é de 25,8으 C, enquanto que nas regiões mais próximas de Manaus, AM, as temperaturas podem atingir $27,9^{\circ} \mathrm{C}$ nos meses de setembro e abril (FISCH et al., 1998; 
BRASIL, 2005; RONDÔNIA, 2019).

\section{REVISÃO TEÓRICA}

\section{Erosão}

A ineficiência em dissociar a própria energia disponível de um determinado sistema ambiental (clima, substrato rochoso, relevo, solo e vegetação) que está em desequilíbrio, resulta em processos que pode atingir um novo estado de equilíbrio, causando erosão tanto natural (erosão natural ou geológica) quanto antrópica (erosão acelerada) (BACK, 1997).

No caso da erosão natural ou geológica, como parte essencial na evolução das paisagens naturais, ela está associada a processos de intemperismo responsáveis pela formação dos solos em tempo geológico e produziu diversos tipos de topografia atuais. Sob condições de erosão natural, a formação de solo e a erosão desenvolveram através dos tempos os solos hoje existentes. A cobertura vegetal é de vital importância para a manutenção do estado de equilíbrio e qualquer alteração que nela se produza tende a conduzir à erosão acelerada. A erosão natural ou geológica que se manifesta como uma ocorrência normal dos processos de modificação da superfície terrestre é reconhecível somente com o decorrer de longos períodos de atividade (BERTONI et al., 2005).

Quando o processo erosivo é mais veloz que a formação do solo, havendo uma ruptura no equilíbrio natural do meio, ocorre a erosão acelerada ou antrópica, caso tenha sido provocada pela ação humana. A erosão natural ou geológica cede lugar à erosão acelerada como resposta do meio em busca de novas condições de estabilidade em função da substituição da vegetação natural por outro tipo de cobertura vegetal, o qual não proporciona proteção eficiente contra a erosão, dificultando o estabelecimento do processo pedogenético que recomporia a camada erodida (GUERRA et al., 2006).

Dentre as formas de erosão, a hídrica é a que apresenta ação mais intensiva. Seus efeitos estão relacionados a ação do salpicamento ocasionado pelo impacto da chuva no solo, pelo transporte de suas partículas desprendidas, além do escoamento superficial em lençol (PALMEIRA, 2004).

São nas vertentes onde os processos erosivos ocorrem de forma mais acelerada. Fato explicado em parte pelo efeito gravitacional nas águas pluviais, mas sobretudo pela interferência antrópica na alteração da cobertura e, até, no padrão estrutural dos taludes. Fazendo, desse modo, o solo receber de forma mais intensa os efeitos diretos da chuva e do 31 escoamento superficial e, consequentemente, aumento da quantidade de material erodido e transportando (CASSETI, 1991; BERTONI et al., 2005).

Outro fator importante relacionado à capacidade de resistência a erosão do solo é a influência que o controle estrutural do terreno exerce sobre o fluxo do escoamento superficial. A esse respeito Pastore et al. (1998) explicam que as estruturas de faturamento são reflexos do material geológico de origem e, portanto, representam a figura reliquiar da rocha mãe. Assim, à medida que o escoamento superficial ganha velocidade, o seu fluxo passa a criar canaletas dando forma linear as feições erosivas, as flow line, e os atritos entre as partículas contribuem para com o aumento da erosão nestes canais de escoamento, desprendo 
cumulativamente a maior quantidade possível de materiais (BERTONI et al., 2005; GUERRA, 2007; CHEROBIN, 2012). Por conseguinte, formam-se os sulcos e ravinas, que são feições erosivas de estágios sequenciais podendo evoluir para o estágio de voçorocamento (BIGARELLA et al., 2007).

Segundo Lepsch (2002) a maior ou menor suscetibilidade de um terreno a erosão pela água depende de uma série de fatores dos quais quatro são considerados principais, são eles: as chuvas, que quando caem em grandes quantidades em curtos períodos e ultrapassam a capacidade de absorção do solo provocam grandes enxurradas que poderá causar grandes erosões; a natureza do solo, solos com textura arenosa, menos permeáveis, pouco profundos e com baixa fertilidade natural são mais propícios a erosão; declividade do terreno, influencia na concentração, dispersão e velocidade da enxurrada e consequentemente no maior ou menor arrastamento superficial das partículas de solos; e, finalmente, manejo do solo, o modo como a terra é manejada e o sistema de cultivo estão diretamente envolvidos na maior ou menor mobilidade dos solos.

\section{Ecodinâmica}

A ecodinâmica pode ser compreendida como uma proposta metodológica capaz de avaliar os impactos que as ações antrópicas causam nos diferentes componentes de um determinado ambiente natural (TRICART, 1977). Assim, o autor classifica os ambientes de análise em: meios estáveis, meios integrados e meios fortemente instáveis.

Os meios estáveis representam densa vegetação associada a um relevo com moderada dissecação. Os meios integrados são ambientes de transição e correspondem a áreas onde ocorrem equilíbrio entre os processos de morfogênese e pedogênese. Por outro lado, os meios instáveis são ambientes onde predominantemente ocorrem os processos de morfogênese, ou seja, locais onde há a presença de relevos acentuados e acidentados, alta densidade pluviométrica e baixa densidade de vegetação.

Conforme explica Rodrigues (2001), a ecodinâmica apresenta-se como uma importante ferramenta para estudos voltados à gestão e planejamento territorial. Trata-se da possibilidade de classificar os ambientes conforme a sua instabilidade a partir da compreensão de suas fragilidades ou vulnerabilidades frente às ações antrópicas. Segundo Tricart (1977), a gestão e planejamento territorial sob ótica da ecodinâmica deve ser realizada considerando a caracterização do quadro regional, a análise morfodinâmica, reconhecimento dos recursos ecológicos e a definição dos problemas da gestão do território, fornecendo subsídios para o reconhecimento das potencialidades e fragilidades dos aspectos naturais, possibilitando também estabelecer a sustentabilidade das dinâmicas socioeconômicas inter e intrarregionais.

\section{Vulnerabilidade a erosão}

O estudo da vulnerabilidade a erosão refere-se à avaliação de interferências de fatores naturais erosivos na denominada erosão natural ou geológica (BACK, 1997; BERTONI et al., 2005), com previsão de estimativas de estabilidades e instabilidades naturais a erosão como parte essencial na evolução de paisagens naturais. Crepani et al. (1996; 2001) propõem a determinação do grau de vulnerabilidade a erosão a partir 
do conceito de ecodinâmica de Tricart (1977), por meio de um conjunto de dados espaciais geoprocessados de uma determinada área a partir do cruzamento de informações temáticas de elementos que compõem o ambiente. O trabalho de Gomes (2005), por exemplo, concluiu que o método foi eficiente na identificação das áreas mais vulneráveis em regiões do semiárido, destacando a retirada da cobertura vegetal como uma das principais responsáveis pela formação de processos erosivos, enquanto que as demais variáveis se apresentaram com tendência a prevalência da pedogênese em relação à morfogênese. Já Mesquita (2010) ao aplicar o método em região subtropical (Morretes/PR), verificou que a bacia do rio Sagrado apresenta a geologia resistente e a densa cobertura vegetal como fatores estabilizantes da paisagem, enquanto que a alta declividade e as unidades pedológica presentes mostraram-se bastante vulneráveis. Por outro lado, Oliveira et al. (2011) ao realizarem estudos de vulnerabilidade em ambientes amazônicos (estado do Pará), constataram que mesmo em áreas com uso consolidado a perda de solo se mostrou controlada, haja vista que a configuração geoambiental da área se apresentou estável à erosão. Finalmente, no estado de Rondônia, Mendes et al. (2012) ao estudar a perda de solo em sistemas silvopastoril implantados em unidade de produção familiar verificaram que esses apresentam menor prevalência da morfogênese quando comparados com a produção agrícola tradicional.

\section{METODOLOGIA}

O método utilizado consistiu na aplicação dos princípios do conceito da ecodinâmica de Tricart (1977), que consiste na relação morfogênese, quando prevalecem processos erosivos modificadores das formas de relevo, e pedogênese, quando prevalecem processos formadores de solos. Para tanto, foram utilizados os procedimentos descritos por Crepani et al. (1996; 2001) para a análise da vulnerabilidade a erosão, aplicado também em outras áreas da Amazônia por Silva et al. (2005), Chelly et al. (2008), Gomes et al. (2011), Bastos et al. (2014) e Bastos et al. (2015), por meio de técnicas de geoprocessamento, na escala de trabalho de 1:250.000, trabalhos de campo e, por último, mapeamento final dos polígonos com os índices de vulnerabilidade a erosão.

\section{Análise da vulnerabilidade a erosão}

Para a análise da vulnerabilidade a erosão foram utilizados dados geoespaciais provenientes de informações cartográficas (AMAZONAS, 2011) e imagens do satélite ALOS/PALSAR combinadas para gerar mapas derivados. Os cálculos envolveram arquivos em formato vetorial como representantes das variáveis que compõem a paisagem (Clima, Geologia, Solo, Geomorfologia, Vegetação, Intensidade Pluviométrica e Morfoestrutura), que foram convertidos para o formato raster. Na sequência, utilizou-se a ferramenta denominada Raster Calculator, componente do software ArcGis 10@, onde a partir da álgebra de mapas foram calculados os índices de vulnerabilidade a erosão, obtendo, como resultado, o mapa síntese. Os dados dos elementos ambientais referentes a Geologia, Geomorfologia, Pedologia, Vegetação e Intensidade Pluviométrica, envolveram dados cartográficos do zoneamento socioeconômico e ecológicos do estado do Amazonas disponíveis em Amazonas (2011). 
Os dados referentes aos componentes geomorfológicos foram obtidos a partir do modelo digital de elevação ALOS/PALSAR, com resolução espacial de 12,5 metros, utilizados para mensurar as dimensões interfluviais, amplitude altimétrica e declividade do relevo, conforme a metodologia adotada por Guimarães et al. (2017). Por outro lado, as características dos temas Geologia, Geomorfologia, Pedologia, Vegetação e Intensidade Pluviométrica foram associadas primeiramente de modo individual aos índices de vulnerabilidade a erosão propostos por Crepani et al. (1996; 2001). Na sequência foram realizados os cálculos de vulnerabilidade a erosão com média aritmética dos índices dos temas, conforme Equação 1. Assim, os índices compreendidos de 1,1 a 1,9 referem-se aos temas cuja a integração favorece a pedogênese, os índices de 2,1 a 3 referem-se aos temas cuja integração favorece a morfogênese.

Equação 1

$$
\mathbf{V}=\frac{\mathbf{G}+\mathbf{R}+\mathbf{S}+\mathbf{V g}+\mathbf{C}}{5}
$$

Onde, V: vulnerabilidade a erosão; G: vulnerabilidade para o tema geologia; R: vulnerabilidade para o tema geomorfologia; S: vulnerabilidade para o tema pedologia; Vg: vulnerabilidade para o tema vegetação; e C: vulnerabilidade para o tema pedologia.

\section{Trabalhos de campo}

Os trabalhos de campo foram realizados visando a verificação de características dos elementos ambientais da paisagem para complementação e validação dos polígonos delimitados com os índices de vulnerabilidade a erosão obtidos nos trabalhos de geoprocessamento. Esse trabalho envolveu observações das características da geologia, geomorfologia, pedologia e vegetação, tanto de modo individual desses temas quanto inter-relacionados com seus índices de vulnerabilidade a erosão. Para auxílio das análises posteriores aos trabalhos de campo foram coletadas amostras de rochas e solos, além de registros fotográficos.

\section{RESULTADOS}

\section{Resultados do processamento dos dados geoespaciais}

A partir das características temáticas, Geologia, Geomorfologia, Pedologia, Vegetação e Intensidade Pluviométrica do Baixo Interflúvio do Madeira-Purus, as operações realizadas para geração do mapa de geocampo numérico com os índices de vulnerabilidade a erosão possibilitaram a caracterização de quatro intervalos para cada tema (classes de vulnerabilidade a erosão), são elas: estável, moderadamente estável, medianamente estável/vulnerável e vulnerável. Desta forma, foi possível a obtenção do mapa de vulnerabilidade a erosão com a sobreposição dos índices dos cinco temas (Figura 2).

A distribuição dos índices e das classes de vulnerabilidade a erosão para o tema Geologia, na área de estudo, resultou em índice igual a 3,0, vulnerável, em a 91,56\% da área de estudo. 0 índice 2,0, correspondeu a 8,42\% da área de estudo, representando áreas pertencentes à classe de vulnerabilidade a erosão moderada. Por fim, os índices 1,0, 1,2 e 1,4, classe de vulnerabilidade a erosão Estável, que representam 0,010\% da área de estudo.

Os índices de vulnerabilidade para o tema Geomorfologia foram estabelecidos após a identificação 
após a análise dos subtemas dimensão interfluvial, amplitude altimétrica e declividade. Como resultado 99,97\% de área estudada corresponde a paisagens estáveis, classificadas como pertencentes a classe de vulnerabilidade estável e moderadamente estável.

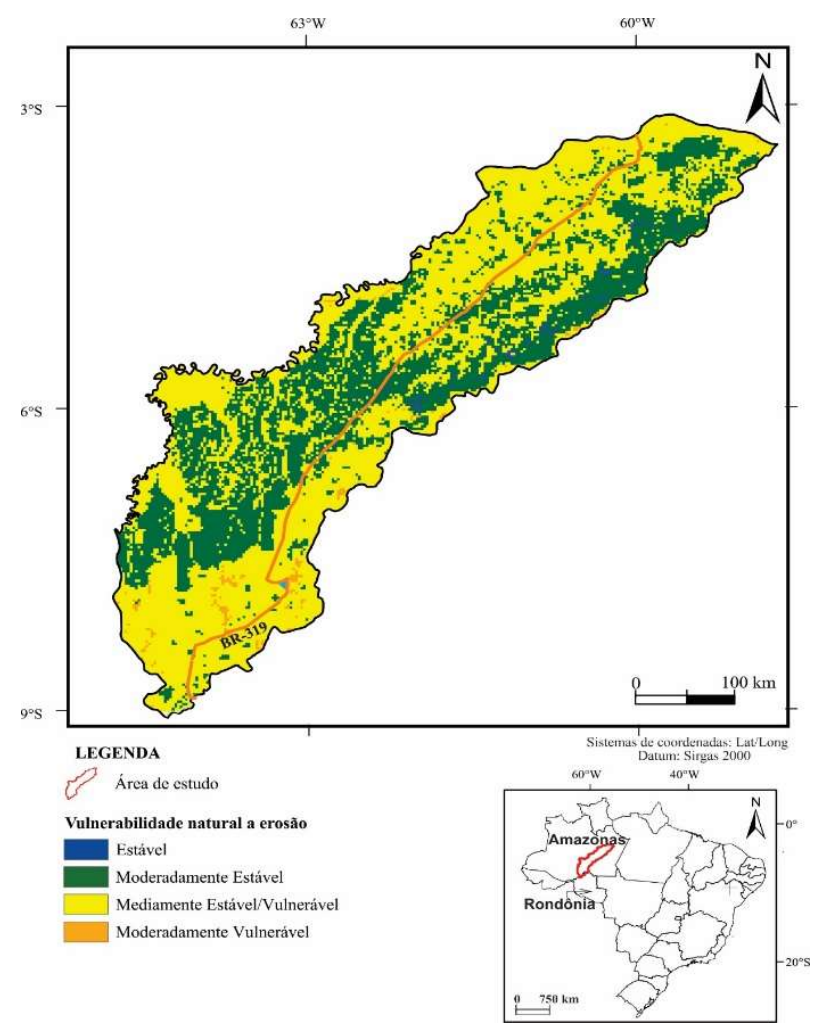

Figura 2: Distribuição espacial das classes de vulnerabilidade a erosão dos temas Geologia, Geomorfologia, Pedologia, Vegetação e Clima (Intensidade Pluviométrica) no Baixo Interflúvio do Madeira-Purus.

Quanto a Pedologia, a predominância da classe de vulnerabilidade a erosão medianamente estável/vulnerável, com índice igual a 2,0, correspondeu a 49,05\%, seguido de porções do terreno com a classe de vulnerabilidade a erosão estável, índice 1,0, que correspondem a $27,53 \%$ da área de estudo, área com classe de vulnerabilidade vulnerável correspondente ao índice 3,0 abrangendo 22,12\% da área de estudo e 1,31\% correspondente a áreas com índice 2,5 com classe de vulnerabilidade referente a moderadamente vulnerável.

Em relação a vegetação, a distribuição dos índices de vulnerabilidade a erosão para o tema Vegetação demonstrou que 89,04\% da área do Baixo Interflúvio do Madeira-Purus exibe alta densidade de cobertura vegetal natural, correspondente a classe de vulnerabilidade estável, e somente $2,82 \%$ da área de estudo são locais recobertos por formações pioneiras e savanas, correspondendo a classe de vulnerabilidade moderada.

Finalmente, em relação a temática Clima, representada pelo peso referente a intensidade pluviométrica, os resultados se apresentaram de forma homogênea classificando a área de estudo como moderadamente estável.

O agrupamento e sobreposição dos valores dos índices de vulnerabilidade a erosão do Baixo Interflúvio Madeira-Purus referente aos temas Geologia, Geomorfologia, Pedologia, Vegetação e Clima (Intensidade Pluviométrica) possibilitaram a representação das classes de vulnerabilidade a erosão em hectares e em porcentagem (Tabela 1), bem como a cartografia de sua distribuição espacial (Figura 2). As 
classes de vulnerabilidade a erosão indicaram características de porções do terreno de estável a moderadamente vulnerável, com a classe mediamente estável vulnerável predominante, recobrindo 61,09\% da área de estudo. Observa-se que em $98,82 \%$ da área de estudo ou há o predomínio de processos formadores de solos (pedogênese) em relação aos processos erosivos modificadores das formas de relevo (morfogênese) ou há o equilíbrio entre esses processos. O restante da área $(1,19 \%)$ é constatado a presença da classe modernamente vulnerável como representante da classe relativamente mais vulnerável a erosão, verificada principalmente nas proximidades das drenagens na porção sul da área de estudo.

Tabela 1: A vulnerabilidade a erosão no Baixo Interflúvio do Madeira-Purus com a integração dos temas Geologia, Geomorfologia, Pedologia, Vegetação e Intensidade Pluviométrica. Os índices e classes de vulnerabilidade foram obtidos de Crepani et al. (2001).

\begin{tabular}{l|l|l|l}
\hline Classes de Vulnerabilidade & Índices de Vulnerabilidade & Área (ha) & Área (\%) \\
\hline Estável & 1,3 & $6.6052,91$ & 0,47 \\
& 1,4 & $34.8213,20$ & 2,47 \\
Moderadamente estável & 1,5 & $544.810,63$ & 3,86 \\
& 1,6 & $3.605 .299,94$ & 25,54 \\
& 1,7 & $761.112,86$ & 5,39 \\
Medianamente estável/vulnerável & 1,8 & $523.4738,55$ & 37,10 \\
& 1,9 & $831.396,28$ & 5,89 \\
& 2,0 & $238.2106,10$ & 16,88 \\
Moderadamente vulnerável & 2,1 & $3.9840,83$ & 0,28 \\
\hline Total & 2,2 & $13.2690,30$ & 0,94 \\
\hline & 2,3 & $16.3013,64$ & 1,15 \\
& 2,4 & $4.463,92$ & 0,03 \\
\hline
\end{tabular}

\section{Resultado dos Trabalhos de Campo}

As observações realizadas durante os trabalhos de campo analisaram a correspondência das informações geradas a partir do uso de geoprocessamento com os processos pedogenéticos e morfogenéticos atuantes, tendo como base os polígonos de diferentes vulnerabilidades obtidos nos trabalhos com o geoprocessamento.

Nesses trabalhos de campo foram identificados materiais detrito-lateríticos desempenhando papel importante na configuração do relevo da área de estudo, do mesmo modo como observado por Nascimento et al. (2012) na área urbana de Porto Velho/RO e na porção sul Baixo Interflúvio Madeira-Purus. As formas de relevo mais exuberantes estão associadas aos lateritos (zona coesa) em função de sua relativa resistência a processos intempéricos atuais. O desenvolvimento de superfícies rebaixadas nas áreas que ocorrem lateritos está associado à paisagem onde afloram materiais ricos em argila (horizonte argiloso) e lateritos desmantelados (zona incoesa).

Foi verificada a presença de terremos contendo lateritas de natureza imatura e ferruginosa como indicativos de paleosuperfícies intensamente drenadas sendo, ora bastante resistentes ao intemperismo, ora desmanteladas como consequência das condições climáticas subatuais e atuais como também observada por Nascimento et al. (2012), Figura 3. Tratam-se de perfis incompletos de diferenciação supergênica com partes do horizonte ferruginoso e suas zonas coesa e incoesa, e/ou partes do horizonte argiloso com suas zonas argilosa vermelha e mosqueada. 


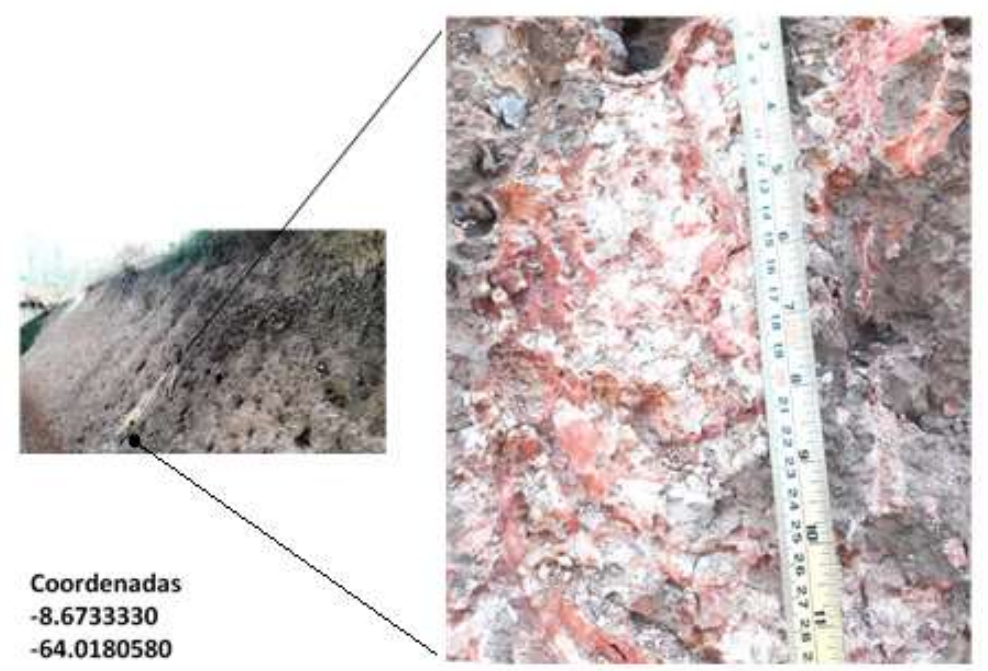

Figura 3: Área parcialmente desflorestadas sob a condição vulnerabilidade moderadamente estável em materiais lateríticos pleistocênicos, horizonte ferruginoso, zona incoesa, com porções de lateritos, zona coesa, em processo de desagregação.

Diferentes intensidades de erosão induzida acelerada são os processos atuantes para a remodelagem da paisagem natural do Baixo Interflúvio do Madeira-Purus, tendo proporcionado rupturas no equilíbrio natural da paisagem que tende a se reequilibrar, ou seja, está em fase de ajuste morfodinâmico em função da mudança da dinâmica das águas pluviais (Figuras 4a e 4b). Nas porções do terreno classificadas como moderadamente estável foi possível observar o desenvolvimento de voçorocas ativas, chegando a profundidade máxima de 1,5 m e desconectadas do lençol freático localizadas nas proximidades de cortes de estrada com baixa a média declividade associados com material sedimentar inconsolidado e de baixa coesão entre seus grãos mal selecionados (Figura 4b). Nas encostas com declividade baixa são observadas remoções de camadas delgadas de solo por meio do escoamento superficial que se distribui de forma dispersa laminar, caracterizando a saturação da capacidade de armazenamento de água no solo (Figura 4a).
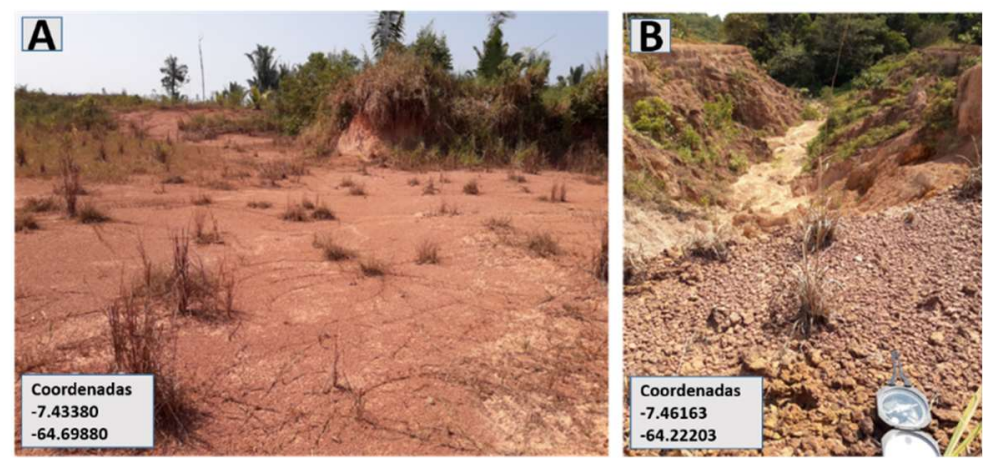

Figura 4: Áreas desflorestadas sob a condição vulnerabilidade moderadamente estável em materiais lateríticos pleistocênicos, com processo de erosão laminar (A) e com voçoroca representando o processo de erosão linear (B).

Nas áreas com características medianamente estável/vulnerável onde a cobertura vegetal natural se encontra preservada, os processos erosivos se mostram imperceptíveis. Porém, em porções do terreno com a ocorrência de alteração antrópica e com média declividade foi observada a ocorrência de início de processos erosivos lineares na forma de ravinas e voçorocas (Figuras 5a e 5b), em função da configuração de caminhos de menor resistência das águas pluviais. 

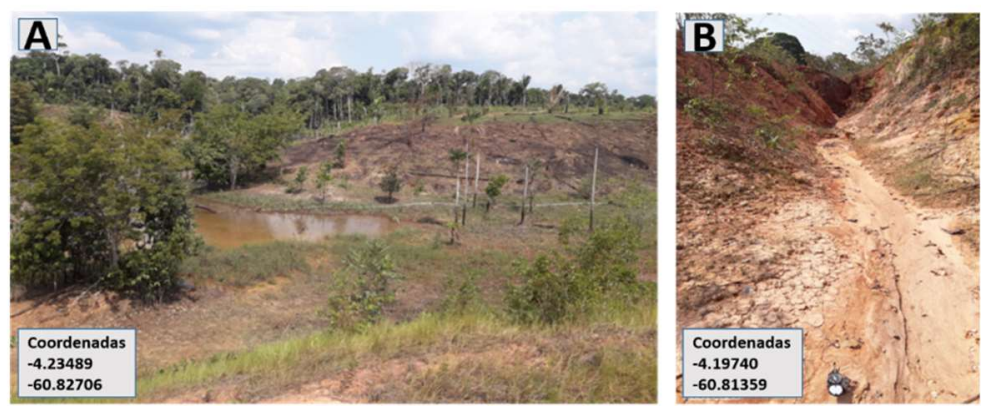

Figura 5: Áreas desflorestadas sob a condição de vulnerabilidade medianamente estável/vulnerável em coberturas sedimentares cenozoicas do Mioceno e Plioceno (Formação Içá), com processo de erosão laminar (A) e com voçoroca representando o processo de erosão linear (B).

Embora apresente vulnerabilidade próxima ao vulnerável (cor laranja na legenda da Figura 2), nas porções do terreno sob condições de vulnerabilidade a erosão moderadamente vulnerável foi verificada a ausência de ocorrências de processos erosivos lineares, durante as observações realizadas em campo. Porém essa constatação a partir da remoção da vegetação natural pelas modificações antrópicas pode figurar fatores condicionantes ao desenvolvimento de futuros de processos erosivos laminares e/ou lineares. Essas porções do terreno de vulnerabilidade a erosão moderadamente vulnerável é bastante característica em função de sua cobertura vegetal correspondente a fitofisionomia de Savana (Figura 6).

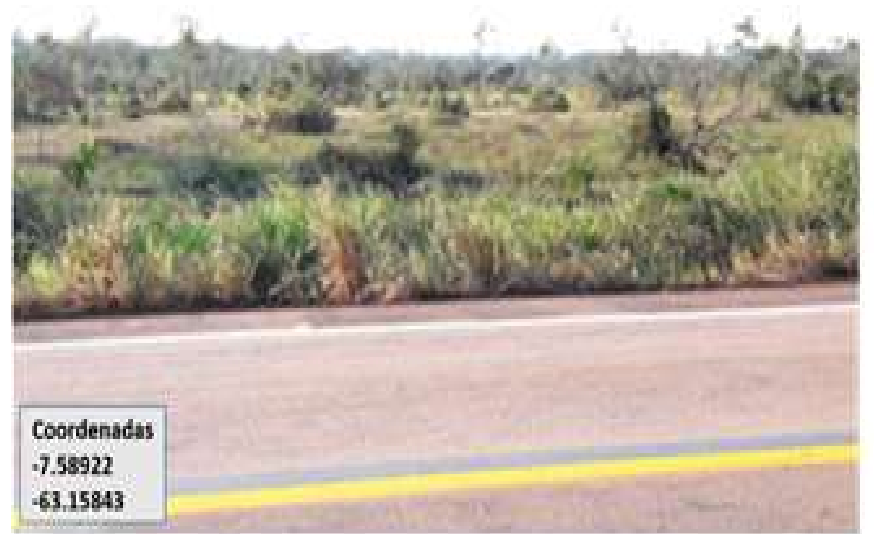

Figura 6: Área sob a condição de vulnerabilidade moderadamente vulnerável em coberturas sedimentares cenozoicas (Mioceno e Plioceno) da Formação Içá, com fitofisionomia de savana.

\section{DISCUSSÃO}

A predominância na área de estudo do equilíbrio entre pedogênese e morfogênese se estabelece sobretudo a partir do contraponto entre a cobertura vegetal associada ao relevo e ao tipo de material geológico. Onde os primeiros respectivamente são representados preferencialmente por densas florestas ombrófilas e terreno relativamente plano, enquanto que o segundo é representado por coberturas sedimentares cenozoicas inconsolidadas.

As demais variáveis, por sua vez, também se figuram em maior parte com característica de vulnerabilidade a erosão tendendo para estável, sendo que a variável Pedologia apresenta 76,58\% da área de estudo sob condições de vulnerabilidade estável ou medianamente estável/vulnerável e os índices de precipitação em sua totalidade de vulnerabilidade moderadamente estável. Portanto, a classificação dada a variável Clima para a área de estudo, a partir da precipitação pluviométrica como moderadamente estável, 
ocorre em virtude de os índices de precipitação estarem compreendidos entre 2.000 e 2.300 mm/ano.

A composição dos materiais geológicos que se apresenta predominante vulnerável na área de estudo, ocorre em função das coberturas sedimentares cenozoicas da Formação Içá (Mioceno e Plioceno) e dos Terraços e Aluviões Holocênicos, constituídos por sedimentos com baixa coesão entre seus grãos. Em menor proporção, a vulnerabilidade a erosão moderada se apresenta em virtude da ocorrência de cobertura laterítica pleistocênica, a qual possui grau de coesão de seus materiais superior aos materiais sedimentares e inferior às rochas magmáticas e metamórficas e, por fim, a vulnerabilidade estável que se encontra com pouca representatividade na área de estudo, é constituída por rochas graníticas das Suítes Intrusivas Santo Antônio e Teotônio e por rochas gnáissicas do Complexo Jamari.

A influência da cobertura vegetal por sua vez, representada predominantemente por florestas ombrófilas, apresenta alto fator de proteção contra os processos morfogenéticos que se traduzem na forma de erosão, enquanto que as áreas com vegetação de savanas, em menor proporção, apresentam naturalmente baixa proteção da fitogeografia à ação das águas pluviais.

O relevo demonstra que $99,97 \%$ da área de estudo apresenta preferencialmente características que contribuem mais para a ocorrência de processos formadores de solos (pedogênese) em relação aos processos erosivos modificadores das formas de relevo (morfogênese), onde em $98,92 \%$ da área de estudo o relevo varia de plano a suavemente ondulado, segundo a classificação de EMBRAPA (1999), com a declividade inferior a 6 graus, a amplitude altimétrica em sua maioria se apresenta inferior a 20 metros, porém a dimensão interfluvial em maior representatividade se apresenta entre as porções do terreno de vulnerabilidade medianamente estável/vulnerável e vulnerável, em virtude de $87,59 \%$ da área estudo possuir dimensão entre os canais fluviais menores que 3.250 metros.

A variável Pedologia demonstrou predominância da classe vulnerabilidade a erosão medianamente estável/vulnerável e estável, em função da ampla distribuição dos Argissolos que embora não sejam bem desenvolvidos e profundos, sua camada de argila entre os horizontes A e B garante maior resistência a perda natural dos constituintes do solo. Os Latossolos, por sua vez, além de apresentarem uma concentração residual de sesquióxidos (óxido de alumínio e óxido de ferro) e argila do tipo 1:1, possuem, também, boas condições de permeabilidade à água e ao ar, e mesmo com alta porcentagem de argila são porosos, friáveis e de baixa plasticidade.

As observações realizadas durante os trabalhos de campo confirmaram os resultados obtidos nos trabalhos de geoprocessamento, que a paisagem em seu estado natural se apresenta predominantemente estável ou próximo à estabilidade quanto a vulnerabilidade a erosão. Já nos locais onde ocorreram antropização por meio de desflorestamento, nas porções do terreno de vulnerabilidade moderadamente estável e medianamente estável/vulnerável os processos erosivos se instalaram tanto na forma laminar como também na forma linear com ravinas e voçorocas.

\section{CONCLUSÕES}

Os dados geoespaciais dos temas Geologia, Geomorfologia, Pedologia, Vegetação e Clima que 
compõem a paisagem do Baixo Interflúvio Madeira-Purus possibilitaram a avaliação do funcionamento dinâmico entre os sistemas geoambientais, com a identificação de potencialidades de porções do terreno com relação a vulnerabilidade a erosão. Os diferentes índices de vulnerabilidade a erosão da paisagem proporcionaram a distinção de quatro classes, são elas: estável $(0,47 \%)$, moderadamente estável $(37,26)$, medianamente estável/vulnerável (61,09\%) e moderadamente vulnerável (1,18\%).

Processos erosivos intensos, principalmente os lineares, ravinas e voçorocas, são possíveis de ocorrerem nas porções do terreno a partir da supressão da vegetação natural, como observado durante a realização dos trabalhos de campo nas porções do terreno de vulnerabilidade a erosão classificadas como moderadamente estável e medianamente estável/vulnerável.

Por fim, os resultados obtidos neste trabalho preveem a necessidade de avaliar outras variáveis que justifiquem potencialização dos processos erosivos laminares e lineares encontrados em campo, ocasionando o desarranjo no sistema natural do ambiente com novos ajustes morfodinâmicos. Isto no que diz respeito às futuras tomadas de decisões socioambientais sustentáveis de ocupação antrópica para atividades agropecuárias e obras de infraestrutura no Baixo Interflúvio do Madeira-Purus com a iminente revitalização da rodovia BR-319 como a única ligação rodoviária do estado do Amazonas com o restante do Brasil e a possibilidade da conexão desta área com o arco de desmatamento e vigorosa antropização.

\section{REFERÊNCIAS}

AMAZONAS. Governo do Estado. Zoneamento ecológicoeconômico da sub-região do Purus: situação atualzoneamento ecológico-econômico da sub-região do Purus. Relatório v.2. Manaus: Governo do Estado, 2011.

BACK, P.. How nature works, the science of self-organized criticality. Oxford University Press, 1997.

BASTOS, A. S.; MANIESI, V.; PASSOS, E.; GOMES, F.; UCHÔA, L. F.. Physical environment aspects as subsidy to occupation in southwest Amazon conservation units: A case study relating to the Jamari National Forest and its surrounding areas. International Journal of Environment and Sustainability, v.2, n.2, p.9-22, 2014.

BASTOS, A. S.; MANIESI, V.; GOMES, F. B.. Vulnerabilidade natural à erosão no sudoeste da Amazônia associada aos seus modos de ocupação. $\mathrm{O}$ caso do entorno da Terra Indígena Uru Eu Wau Wau. Revista Brasileira de Geomorfologia, v.16, p.271-282, 2015.

BECKER, B. K.. Geopolítica da Amazônia. Estudos Avançados, v.19, p.71-86, 2005.

BERTONI, J.; LOMBARD NETO, F. L.. Conservação do solo. São Paulo, 2005.

BIGARELLA, J. J.; BECKER, D. B.; SANTOS, G. F.. Estrutura e origem das paisagens tropicais e subtropicais. Florianópolis, 2007.

BRASIL. Precipitação anual média do Brasil. Mapa Digital. Brasília: Ministério do Meio Ambiente, 2005.

BRASIL. Departamento Nacional de Infraestrutura de
Transportes. Contratação de empresa especializada para a elaboração de estudos e projetos básico e executivo de engenharia para pavimentação e melhoramentos, incluindo obras de artes especiais, do "Trecho do Meio" da rodovia BR-319/AM, referente ao trecho do $\mathrm{km} \mathrm{250,70} \mathrm{ao}$ km 656,40 (SNV201903A). Brasília: DNIT, 2019.

CASSETI, V.. Dinâmica processual do relevo: a vertente como categoria. Ambiente e apropriação do relevo. São Paulo: Contexto, 1991.

CHELLY, R.; MANIESI, V.. Vulnerabilidade à erosão no município de Rio Branco, Acre: aplicação de técnicas de geoprocessamento. In: SEMINÁRIO INTERNACIONAL AMAZÔNIA E FRONTEIRAS DO CONHECIMENTO, NÚCLEO DE ALTOS ESTUDOS AMAZÔNICOS - NAEA/UFPA, Anais. Belém, 2008. p.17.

CHEROBIN, S. F.. Estimativa de erosão e sua relação com os diferentes mecanismos erosivos atuantes: estudo da voçoroca Vila Alegre. Dissertação (Mestrado em Engenharia Ambiental) - Universidade Federal de Ouro Preto, Ouro Preto, 2012.

CREPANI, E.; MEDEIROS, J. S.; AZEVEDO, L. G.; HERNANDEZ FILHO, P.; FLORENZANO, T. G.; DUARTE, V.. Curso de sensoriamento remoto aplicado ao zoneamento ecológicoeconômico. São José dos Campos: INPE, 1996.

CREPANI, E.; MEDEIROS, J. S.; HERNANDEZ FILHO, P.; FLORENZANO, T. G.; DUARTE, V.; BARBOSA, C. C. F.. Sensoriamento remoto e geoprocessamento aplicados ao zoneamento ecológico: econômico e ao ordenamento territorial. São José dos Campos: INPE, SP, 2001. 
EMBRAPA. Centro Nacional de Pesquisa de Solos. Sistema brasileiro de classificação de solos. Rio de Janeiro: EMBRAPA-SP, 1999.

FEARNSIDE, P. M.. A ocupação humana de Rondônia: impactos, limites e planejamento. Brasília: Assessoria Editorial e Divulgação Científica, 1989.

FEARNSIDE, P. M.. Migração, colonização e meio ambiente: o potencial dos ecossistemas amazônicos. In: CONFERÊNCIA INTERNACIONAL SOBRE MEIO AMBIENTE, DESENVOLVIMENTO E SAÚDE. Anais. Rio de Janeiro: Fundação Oswaldo Cruz, 1993. p.448-457.

FEARNSIDE, P. M.; GRAÇA, P. M. L. A.. Br-319: a rodovia Manaus-Porto Velho e o impacto potencial de conectar o arco de desmatamento à Amazônia. Novos Cadernos NAEA, v.12, n.1, p.19-50, 2009.

FISCH, G.; MARENGO, J. A.; NOBRE, C. A.. Uma revisão geral sobre o clima da Amazônia. Acta Amazônica, v.28, n.2, São José dos Campos, 1998.

GOMES, A. G.. Avaliação da vulnerabilidade à perda de solo em região semiárida utilizando sensoriamento remoto e geoprocessamento: área piloto de Parnamirim (PE). INPE, 2005.

GOMES, F. B.; BASTOS, A. S.; VARGAS, B.; CASTRO, M. M.. Estudo de vulnerabilidade natural à erosão como subsídio para recuperação de áreas degradadas no entorno da Floresta Nacional do Jamari/RO. In: CONGRESSO BRASILEIRO DE CARTOGRAFIA, 25. Anais. Curitiba, 2011. p.747-754.

GUERRA, A. J. T.. O início do processo erosivo. In: GUERRA, A. J. T.; SILVA, A. S.; BOTELHO, R. G. M.. Erosão e conservação dos solos: conceitos, temas e aplicações. 3 ed. Rio de Janeiro: Bertrand Brasil, 2007.

GUERRA, A. J. T.; CUNHA, S. B.. Geomorfologia e meio ambiente. 6 ed. Rio de Janeiro: Bertrand Brasil, 2006.

GUIMARÃES, F. S.; CORDEIRO, C. M.; BUENO, G. T.; CARVALHO, V. L. M.; NERO, M. A.. Uma proposta para automatização do índice de dissecação do relevo. Revista Brasileira de Geomorfologia, v.18, p.155-167, 2017.

IBGE. Instituto Brasileiro de Geografia e Estatística. Manual técnico de pedologia. 2 ed. Rio de Janeiro: IBGE, 2007.

LEAL, M. L.; MANIESI, V.. Dinâmica de desflorestamento nos assentamentos extrativistas do município de Humaitá, Amazonas. Revista de Geografia e Ordenamento do Território (GOT), n.14, p.251-266, 2018a.

LEAL, M. L.; MANIESI, V.. O desflorestamento e suas relações com as legislações federais: uma análise sobre os assentamentos rurais do município de Manicoré/AM. Estudos Geográficos, Rio Claro, v.16, n.1, p.24-40, 2018b.

LEPSCH, I. F.. Formação e conservação dos solos. São Paulo: Oficina de Texto, 2002.

MENDES, A. M.; SILVA, A. A.; SALMAN, A. K. D.

Vulnerabilidade a perda do solo nos sistemas silvopastoris implantados em unidades de produção familiar no estado de Rondônia. In: SEMINÁRIO DE AGROECOLOGIA DO MATO GROSSO DO SUL, 4. Anais. Glória de Dourados, 2012.

MESQUITA, C.; ASSIS, A. Q. S.; SOUZA, R. M.. Vulnerabilidade natural à perda do solo da bacia hidrográfica do rio Salgado - Morretes, PR. Revista de Geografia, Recife, v.27, n.2, 2010. DOI: http://doi.org/10.51359/2238-6211.2010.228872

NASCIMENTO, T. C. N.; MANIESI, V.; ADAMY, A.; SANTOS, A. N.. A Natureza e aplicação dos materiais lateríticos na área urbana e entorno de Porto Velho/RO. Revista Geonorte, Manaus, v.2, n.4, p.11-19, 2012.

OLIVEIRA, R. R. S.; WATRIN, O. S.; VALENTE; M. A.; PIMENTEL, G. M.. Análise da vulnerabilidade natural dos solos à erosão como subsídio ao planejamento territorial em área da microbacia do igarapé Peripindeua, nordeste paraense. In: SIMPÓSIO BRASILEIRO DE SENSORIAMENTO REMOTO, 15. Anais. Curitiba, 2011.

PALMEIRA, A. F.. Técnicas de sensoriamento remoto e geoprocessamento aplicadas à gestão do território do município de Paragominas (estado do Pará). Dissertação (Mestrado em Sensoriamento Remoto) - Instituto Nacional de Pesquisas Espaciais, São José dos Campos, 2004

PASTORE, E. L.; FORTES, R. M.. Caracterização e classificação dos solos. In: OLIVEIRA, A. M.; BRITO, S. N.. Geologia de engenharia, São Paulo: Associação Brasileira de Geologia de Engenharia, 1998.

RODRIGUES, C.. A teoria geossistêmica e sua contribuição aos estudos geográficos e ambientais. Revista do Departamento de Geografia, São Paulo, v.14, n.1, p.69-77, 2001.

RONDÔNIA. Secretaria de Estado do Desenvolvimento Ambiental. Boletim Climatológico de Rondônia 2019. Porto Velho: SEDAM, 2019.

SILVA, L. P.; MANIESI, V.. Avaliação dos limites de uso e ocupação da sub-bacia do rio Enganado - Rondônia, com auxílio de técnicas de geoprocessamento: uma proposta de uso sustentável. Revista Geociências, v.4, n.3, p.267-276, 2005.

TRICART, J.. Ecodinâmica. Rio de Janeiro: IBGE, 1977.

A CBPC - Companhia Brasileira de Produção Científica (CNPJ: 11.221.422/0001-03) detém os direitos materiais desta publicação. Os direitos referem-se à publicação do trabalho em qualquer parte do mundo, incluindo os direitos às renovações, expansões e disseminações da contribuição, bem como outros direitos subsidiários. Todos os trabalhos publicados eletronicamente poderão posteriormente ser publicados em coletâneas impressas sob coordenação da Sustenere Publishing, da Companhia Brasileira de Produção Científica e seus parceiros autorizados. Os (as) autores (as) preservam os direitos autorais, mas não têm permissão para a publicação da contribuição em outro meio, impresso ou digital, em português ou em tradução. 